\title{
Ethanol Inhibits Persistent Activity in Prefrontal Cortical Neurons
}

\author{
Yali Tu, Sven Kroener, Kenneth Abernathy, Christopher Lapish, Jeremy Seamans, L. Judson Chandler, and \\ John J. Woodward \\ Department of Neurosciences and Center for Drug and Alcohol Programs, Medical University of South Carolina, Charleston, South Carolina 29425
}

\begin{abstract}
Cognitive functions supported by neurons in the prefrontal cortex (PFC) are disrupted by acute and chronic exposure to alcohol, yet little is known about the mechanisms that underlie these effects. In the present study, in vivo and in vitro electrophysiology was used to determine the effects of ethanol on neuronal firing and network patterns of persistent activity in PFC neurons. In vivo, ethanol $(0.375-3.5$ $\mathrm{g} / \mathrm{kg}$ ) dose-dependently reduced spike activity in the PFC measured with multielectrode extracellular recording in the anesthetized rat. In an in vitro coculture system containing slices of PFC, hippocampus, and ventral tegmental area (VTA), ethanol (25-100 mM) decreased persistent activity of PFC neurons, but had little effect on firing evoked by direct current injection. Persistent activity was often enhanced after ethanol washout and this effect was maintained in cultures lacking the VTA. A low concentration of the NMDA antagonist APV (5 $\mu \mathrm{M})$ mimicked the inhibition of ethanol of persistent activity with no change in activity after washout. Ethanol inhibition of spontaneous and VTA-evoked persistent activity was enhanced by the D1 dopamine receptor antagonist SCH23390 [R(+)-7-chloro-8-hydroxy-3methyl-1-phenyl-2,3,4,5-tetrahydro-1 $H$-3-benzazepine hydrochloride]. The results of this study show that ethanol inhibits persistent activity and spike firing of PFC neurons and that the degree of ethanol inhibition may be influenced by D1 receptor tone. Ethanol-induced alterations in the activity of deep-layer cortical neurons may underlie some of the behavioral effects associated with ethanol intake.
\end{abstract}

Key words: alcohol; bistability; electrophysiology; slice culture; addiction; NMDA

\section{Introduction}

Alcohol disrupts behaviors and responses that require neurons in the prefrontal cortex (for review, see Moselhy et al., 2001). For example, ethanol reduces the detection of performance errors as monitored by scalp electrodes and decreases EEG activity evoked by stimulation of the prefrontal cortex (Ridderinkhof et al., 2002; Kahkonen et al., 2003). Long-term alcohol abuse causes changes in gray and white matter volume in the PFC that are correlated with the appearance of neurocognitive deficits (for review, see Sullivan and Pfefferbaum, 2005). In functional studies, human alcoholics show significant reductions in event-related oscillations in the frontal cortex during tests that require prefrontal processing (Kamarajan et al., 2004). Decreases in both $\delta$ and theta power in these subjects are greater during no-go trials, suggesting impairments in response inhibition. These findings suggest that alcohol disruption of PFC activity may contribute to the development and persistence of alcohol addiction (Goldman-Rakic, 1999; Kalivas et al., 2005). Despite evidence linking alcohol to impaired cortical function, little is known about the direct effects of ethanol on the behavior of individual PFC neurons.

\footnotetext{
Received Dec. 13, 2006; revised March 26, 2007; accepted March 28, 2007.

This work was supported by National Institutes of Health Grants P50AA10761 (Charleston Alcohol Research (enter), R01AA010983 (L.J.C.), and R01AA09986 and K02AA00238 (J.J.W.).

Correspondence should be addressed to Dr. John J. Woodward, Department of Neurosciences, 173 Ashley Avenue, Suite 403B, P.0. Box 250510, Medical University of South Carolina, Charleston, SC 29425. E-mail: woodward@musc.edu.

D0I:10.1523/JNEUROSC1.5378-06.2007

Copyright $\odot 2007$ Society for Neuroscience $\quad$ 0270-6474/07/274765-11\$15.00/0
}

Neurons within deep layers of the PFC display dynamic patterns of electrical activity during wakefulness that reflect their critical role in integrating inputs from cortical and subcortical structures. Untangling the mechanisms that regulate this activity is complicated by the number and diversity of these inputs and the presence of short and long neuromodulatory circuits that influence activity. During sleep or anesthesia when sensory input is diminished, $\mathrm{PFC}$ neurons undergo slow oscillations $(0.5-1 \mathrm{~Hz})$ in membrane potential between hyperpolarized down states and depolarized up states. Down states are periods of neuronal quiescence whereas up states reflect depolarization driven by synaptic activity (Steriade et al., 1993; O'Donnell and Grace, 1995; Lewis and O'Donnell, 2000). Activity during these up states is one source of the neocortical $\delta$ frequency observed in human EEG studies and is distinct from the slow oscillation (Steriade, 2001). Although these forms of activity are most often associated with loss of consciousness, slow oscillations and persistent activity may be important in strengthening and consolidating changes in synaptic plasticity that underlie various behaviors including certain forms of memory (Steriade, 2001; Marshall et al., 2006). Neuromodulators such as dopamine (DA) released by neurons located in the ventral tegmental area (VTA) influence the activity and excitability of PFC neurons (Lewis and O'Donnell, 2000; Seamans et al., 2003). These signals may allow prefrontal networks to attend to inputs that convey motivational or reward information, including those from alcohol and other drugs of abuse (Goldman-Rakic, 1999; Durstewitz et al., 2000).

In the present study, the effects of ethanol on neuronal activity 
within the PFC was investigated using in vivo and in vitro recording techniques. Because acute slices of cortex rarely show persistent activity, we used a slice coculture preparation that reproduces activity patterns similar to those observed in vivo (Seamans et al., 2003). The results of these studies demonstrate that acute ethanol alters persistent activity of deep-layer pyramidal neurons in the PFC at concentrations that are known to impair behavior.

\section{Materials and Methods}

Animals

All procedures involving animals were conducted under protocols approved by the Institutional Animal Care and Use Committee of the Medical University of South Carolina.

\section{Organotypic slice cocultures}

Slice cocultures were prepared as described previously (Seamans et al., 2003). Briefly, postnatal day 1-3 rat or mouse pups were killed and brains were placed in ice-cold, sucrose-substituted Ringer's solution containing (in mM) 200 sucrose, $1.9 \mathrm{KCl}, 1.2 \mathrm{Na}_{2} \mathrm{HPO}_{4}, 33 \mathrm{NaHCO}_{3}, 6 \mathrm{MgCl}_{2}, 0.5$ $\mathrm{CaCl}_{2}, 10$ glucose, and 0.4 ascorbic acid bubbled with $95 \% \mathrm{O}_{2} / 5 \% \mathrm{CO}_{2}$. Individual coronal sections containing the prelimbic and infralimbic regions of the prefrontal cortex, the midbrain containing the ventral tegmental area, and the hippocampus were cut at a thickness of $350 \mu \mathrm{m}$ using a Leica (Nussloch, Germany) VT-1000 vibratome. Slices were oriented adjacent to one another on a Millipore (Temecula, CA) millicell insert in a six-well culture dish. Each well contained $1 \mathrm{ml}$ of serumcontaining media consisting of 50\% basal medium Eagle, 25\% Earle's balanced salt solution, $25 \%$ horse serum with $37 \mathrm{mg} / \mathrm{ml}$ glucose, $25 \mathrm{~mm}$ HEPES, $100 \mu \mathrm{g} / \mathrm{ml}$ streptomycin, and $0.235 \mathrm{~mm}$ Glutamax. After $3 \mathrm{~d}$ in culture, the media was changed to one containing reduced amounts of horse serum (5\%). After $15 \mathrm{~d}$ in culture, 5-fluoro-2-deoxyuridine (0.08 $\mathrm{mm}$ ) was added to prevent glial overgrowth. Cell culture dishes were kept in a humidified incubator equilibrated with $5 \% \mathrm{CO}_{2}$ and were maintained for $15-40 \mathrm{~d}$ with media changes every $2-3 \mathrm{~d}$. In some experiments examining the effects of ethanol on VTA dopamine neuron activity, cultures were prepared from transgenic mice that express green fluorescent protein (GFP) under the control of a tyrosine hydroxylase promoter (Matsushita et al., 2002).

\section{Electrophysiology}

In vivo recordings. Spontaneous firing of PFC neurons was monitored in vivo using a multielectrode recording system. Sprague Dawley rats (250$350 \mathrm{~g})$ were anesthetized with urethane $(1.5 \mathrm{~g} / \mathrm{kg}$, i.p.) and a 32-channel probe $(8 \times 1$ tetrode assembly, NeuroNexus Technologies, Ann Arbor, MI) was lowered into the PFC using a stereotactic guide. The final coordinates relative to the center of the multiarray probe were (in millimeters from bregma) +2.7 anteroposterior, +0.7 mediolateral, and -3.0 dorsoventral. Each of the eight probe arms ( $15 \mu \mathrm{m}$ thick, $2 \mathrm{~mm}$ long, $200 \mu \mathrm{m}$ separation) contained four electrodes (electrode area, $312 \mu \mathrm{m}^{2}$ ) that were separated by $25 \mu \mathrm{m}$ (see Fig. $1 \mathrm{~A}$ ). Data were acquired at $10 \mathrm{kHz}$ using a Multichannel Systems (Reutlingen, Germany) extracellular recording system and were stored off-line for additional processing. Spike sorting and clustering were performed using Off-line Sorter software (Plexon, Dallas, TX) and records were imported into NeuroExplorer (Nex Technologies, Littleton, MA) for spike-train analysis.

In vitro recordings. For in vitro recordings, the section of the Millipore membrane containing a slice coculture was carefully removed from the insert and was submerged in a recording chamber. The slice coculture was perfused at $\sim 2 \mathrm{ml} / \mathrm{min}$ with artificial CSF (ACSF) containing (in mм) $125 \mathrm{NaCl}, 2.5 \mathrm{KCl}, 25 \mathrm{NaHCO}_{3}, 1.25 \mathrm{NaH}_{2} \mathrm{PO}_{4}, 1.3 \mathrm{MgCl}_{2}, 2 \mathrm{CaCl}_{2}$, 0.4 ascorbic acid, and 10 dextrose. ACSF solutions were maintained at a temperature of $32-33^{\circ} \mathrm{C}$ using a flow-through solution heater and heated recording chamber under thermistor control of a TC-324B temperature controller (Warner Instruments, Hampden, CT). All solutions were continuously bubbled with a mixture of $95 \% \mathrm{O}_{2} / 5 \% \mathrm{CO}_{2}$. Patch pipettes $(1.5 \times 1.1 \mathrm{~mm} ; 4-7 \mathrm{~m} \Omega)$ were filled with an internal recording solution containing (in mM) $120 \mathrm{~K}$-gluconate, $20 \mathrm{KCl}, 0.1 \mathrm{EGTA}, 10 \mathrm{HEPES}, 2$ $\mathrm{Na}_{2} \mathrm{ATP}$, and $0.3 \mathrm{NaGTP}, \mathrm{pH}$ 7.2. In some experiments, biocytin was added to the internal solution to label the patched cell. Liquid junction potential errors were calculated to be $\sim 12 \mathrm{mV}$ and were corrected unless otherwise stated. Whole-cell patch-clamp recordings were made from visually identified deep-layer pyramidal cells from the PFC using a Zeiss (Oberkochen, Germany) FS2 microscope with infrared video/differential interference contrast microscopy. Gigaohm seals were obtained in voltage-clamp mode using an Axoclamp 700A or 700B amplifier (Molecular Devices, Sunnyvale, CA) and the amplifier was switched to current-clamp mode after breakthrough. Pipette access resistance (15-35 $\mathrm{M} \Omega$ ) was monitored throughout the experiment and cells showing a significant deviation in access resistance $(>25 \%)$ were not used for analysis. Data were acquired using an ITC-16 interface (Instrutech, Port Washington, NY) controlled by Axograph 4.9 software running on a Macintosh G4 computer (Apple, Cupertino, CA). For stimulus-evoked responses, square-wave pulses $(0.2 \mathrm{~ms})$ of variable intensity were delivered through a stimulus-isolation unit to a concentric bipolar stimulating electrode visually placed in the slice coculture. At the end of some experiments, slices were processed for tyrosine hydroxylase immunoreactivity as described previously (Seamans et al., 2003) to verify the location of the VTA and the extent of dopaminergic innervation of the PFC. Spontaneous firing of midbrain dopamine neurons was measured in voltage-clamp mode using cell-attached recordings with ACSF in the patch pipette. In some of these experiments, Alexa 594 (Invitrogen) was added to the pipette filling solution and cells were labeled after seal breakthrough after cell-attached recordings. Confocal images were acquired using a Zeiss LSM510 system as described previously (Carpenter-Hyland et al., 2004).

\section{Data analysis}

Unless otherwise noted, data were analyzed for statistical significance using repeated measures one-way ANOVA with post hoc testing where appropriate (Prism 4 software; GraphPad Software, San Diego, CA). A significance level was set at $p<0.05$ for all analyses.

\section{Results}

\section{Ethanol and PFC activity in vivo}

The effect of ethanol on the firing activity of neurons in the prefrontal cortex was determined using multielectrode extracellular recording in urethane-anesthetized rats. Urethane was chosen because it has been reported to have minimal effects on excitatory and inhibitory synaptic responses (Sceniak and Maciver, 2006). In these experiments, each animal tested was given a single dose of ethanol and firing rates of individual neurons were compared before and after ethanol challenge. To quantify the effect of ethanol, mean firing rates were calculated from 5 min recording periods collected just before and $30 \mathrm{~min}$ after administration of ethanol. This period corresponds to the approximate peak of the blood ethanol concentrations after intraperitoneal injection of ethanol. After electrode implantation and a period of recovery (1-2 h), firing rates were relatively constant over time and were not significantly altered after an injection of saline (Fig. 1). In contrast, administration of ethanol to the same animal caused a sustained reduction in spike-firing. The magnitude of ethanol's inhibition of PFC spike-firing was dose dependent. As shown in Figure $1 D, 0.375 \mathrm{~g} / \mathrm{kg}$ ethanol reduced firing by $\sim 20 \%$ whereas firing was inhibited by $\sim 40 \%$ after $0.75 \mathrm{~g} / \mathrm{kg}$ ethanol. Increasing the ethanol dose to $1.5 \mathrm{~g} / \mathrm{kg}$ inhibited firing by $\sim 65 \%$ whereas the $3.5 \mathrm{~g} / \mathrm{kg}$ dose nearly eliminated firing. The blood ethanol concentrations measured $30 \mathrm{~min}$ postinjection ranged from $41.3 \mathrm{mg} / \mathrm{dl}$ $(0.0413 \%)$ for the $0.375 \mathrm{~g} / \mathrm{kg}$ dose to $352.3 \mathrm{mg} / \mathrm{dl}(0.3523 \%)$ for the $3.5 \mathrm{~g} / \mathrm{kg}$ dose (Fig. $1 \mathrm{D})$. These blood levels of alcohol range from subintoxicating $(0.04 \%)$ to sedating $(0.35 \%)$ in the adult rat.

\section{Persistent activity in slice cocultures}

To examine the effects of ethanol on PFC neuron activity in more detail, we performed patch-clamp recordings in slice cocultures 

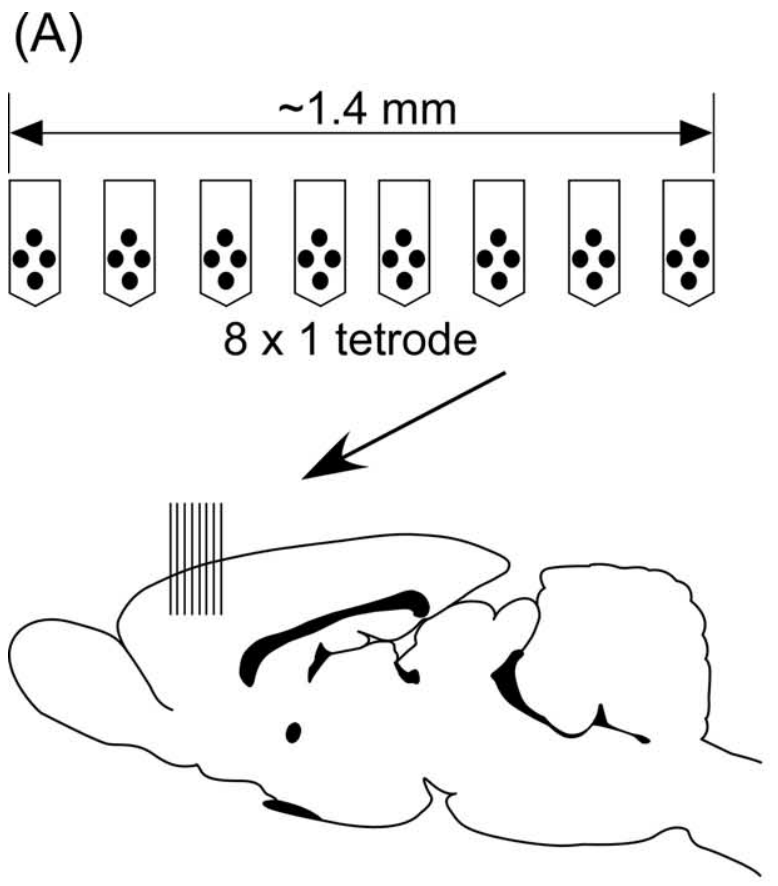

(B)

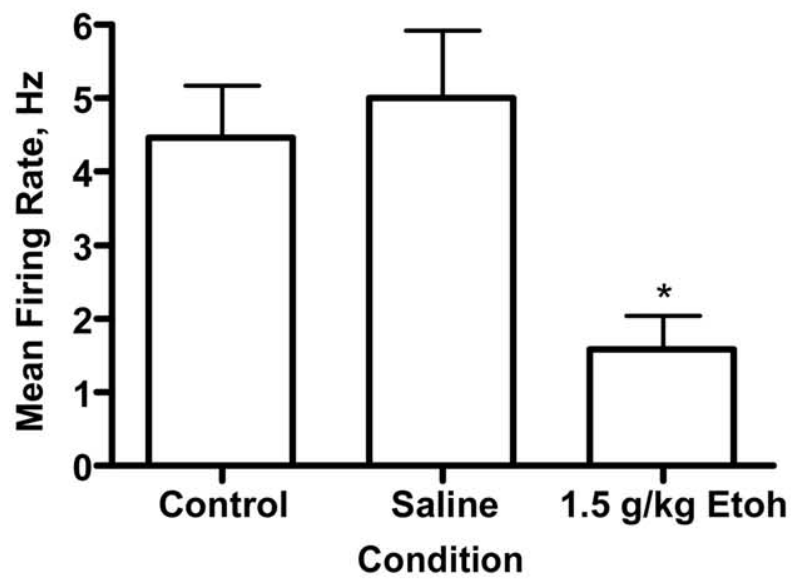

(C)

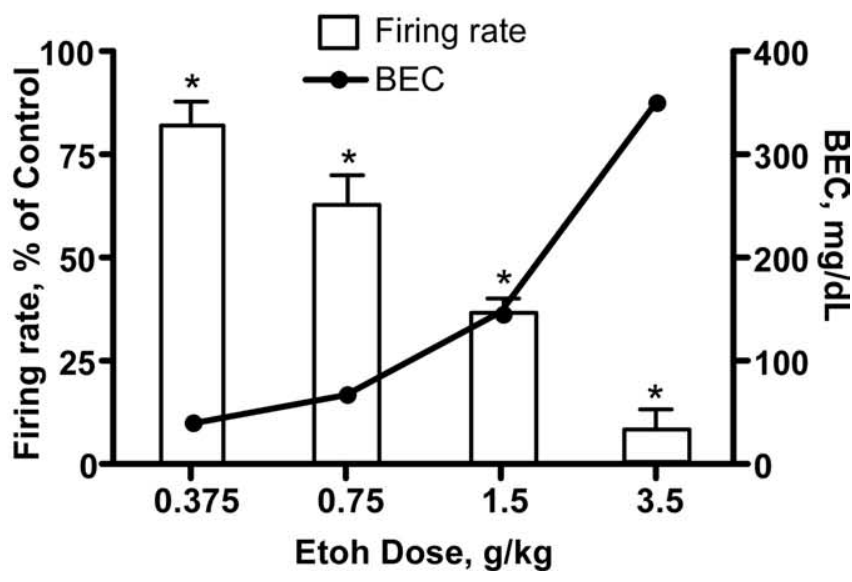

Figure 1. Effects of ethanol on PFC neuron firing in vivo. A, Top, Schematic showing orientation of the electrodes used to record spike activity in the PFC. Each of the eight arms contains four electrodes separated by $25 \mu \mathrm{m}$. Bottom, Sagittal section of the rat brain with the approximate location of the recording electrode (arrow and vertical bars). $\boldsymbol{B}$, Representative exper- containing the PFC, VTA, and hippocampus (Fig. 2). Standard immunohistochemistry for tyrosine hydroxylase $(\mathrm{TH})$ (Seamans et al., 2003), was performed in fixed tissue to verify innervation of the PFC from TH-positive cells in the midbrain slice (Fig. 2A). Similar results with VTA containing cultures have been obtained by other investigators (Franke et al., 2003) and suggest that brain slices maintained in vitro form appropriate synaptic connections and show responses that are similar to those observed in vivo.

Under baseline recording conditions, deep-layer pyramidal neurons displayed membrane bistability reflected as spontaneous transitions from hyperpolarized down states to a depolarized up state (Fig. $2 \mathrm{~B}$ ). Action potential-dependent spiking normally occurred only during up state periods and firing (but not up state transitions) could be suppressed by injection of negative current to bring membrane potentials below threshold for action potential generation (data not shown). The mean ( \pm SEM) frequency of up states recorded from prefrontal neurons in all cultures showing spontaneous activity was $0.11 \mathrm{~Hz}( \pm 0.01)$. The duration of up states and spike-firing during up states varied between slice cocultures, but were relatively constant within an individual neuron during recordings. For 49 control neurons recorded from the PFC area of the slice coculture that showed spontaneous persistent activity, the average membrane potential was $-73.1 \mathrm{mV}$ $( \pm 1.1)$ for the down state and $-57.4( \pm 1.3)$ for the up state. The mean amplitude of depolarization from down state to up state in these neurons was $15.7 \mathrm{mV}( \pm 1.1)$ and the average duration of an up state was $3.7 \mathrm{~s}( \pm 0.5)$. An average of 10.9 spikes per up state $( \pm 1.9)$ was observed with a mean firing rate of $4.7 \mathrm{~Hz}( \pm 0.9)$.

\section{Ethanol and persistent activity}

To examine the effects of ethanol on persistent activity and bistability, a within-subjects experimental design was used. This consisted of recording spontaneous activity from a single deep-layer pyramidal neuron for $\sim 5-10 \mathrm{~min}$ in the absence of ethanol and then switching the perfusion to a solution containing ethanol. The time required for bath exchange between solutions was $\sim 2$ min. Each coculture was exposed to a single concentration of ethanol for $\sim 10 \mathrm{~min}$ before returning to control recording solution. As shown in Figure $2 C, 10 \mathrm{~mm}$ ethanol had little effect on persistent activity or spike activity. In contrast, concentrations of ethanol of $25 \mathrm{~mm}$ and higher significantly inhibited persistent activity (Fig. $2 D, E$ ). At a concentration that is the legal limit for driving in most US states $(0.08 \%$ or $17 \mathrm{~mm})$, ethanol produced noticeable inhibition of spontaneous persistent activity in three of four cells tested (data not shown). To determine whether ethanol affected the intrinsic excitability of deep-layer pyramidal neurons, spike-firing was induced by direct current injections through the patch pipette in the absence and presence of ethanol. As shown in the sample traces in Figure $2 F$, current injection induced regular spiking of deep-layer pyramidal neurons and firing immediately ceased with cessation of the depolarizing current. Ethanol, at concentrations as high as $100 \mathrm{~mm}$, had little significant effect on the current-voltage relationship or on the

$\leftarrow$

iment showing the effect of ethanol on the mean firing rate of PFC neurons. These results are from a single animal and each bar represents the mean ( \pm SEM; $n=13$ neurons per group) firing rate of all neurons measured during a $5 \mathrm{~min}$ period $30 \mathrm{~min}$ after either saline or ethanol $(1.5 \mathrm{~g} / \mathrm{kg}$, i.p.). C, Dose dependence of the ethanol inhibition of PFC firing. Error bars represent the mean ( \pm SEM; $n=15-17$ neurons per concentration; 1 animal for each concentration) percent inhibition (left $y$-axis) of firing by ethanol relative to the control period. Closed circles show the blood ethanol concentration (right $y$-axis) $30 \mathrm{~min}$ after an intraperitoneal injection of ethanol. ${ }^{*}$ Significantly ( $p \leq 0.05$, paired $t$ test) different from corresponding control response. 
rate of firing of deep-layer prefrontal neurons. After washout of the ethanolcontaining solution, firing returned to pre-ethanol control levels.

To quantify the effects of ethanol on spontaneous persistent activity, the amplitude, duration, and number of spikes of individual up states in single neurons were measured before, during, and after exposure to ethanol. For each neuron, these data were expressed as a percentage of the pre-ethanol control value to account for baseline differences in activity between cultures. Figure 3 summarizes the effects of different concentrations of ethanol on up-state amplitude, duration, and the number of spikes per up state. Although ethanol reduced all three parameters in a dose-dependent manner, up-state duration appeared to be more sensitive to inhibition than up-state amplitude, especially at the lower concentrations of ethanol tested. For example, at a concentration of $25 \mathrm{~mm}$, ethanol significantly depressed up-state duration by $\sim 40 \%$, but did not affect up-state amplitude. As the ethanol concentration was increased to $50 \mathrm{~mm}$, up-state amplitude and duration were reduced to $\sim 60$ and $45 \%$, respectively, of the control value and spike activity was inhibited by nearly $80 \%$. A concentration of ethanol of $50 \mathrm{~mm}$ is equivalent to a blood alcohol level of $\sim 0.2 \%$ and is associated with moderate to severe intoxication in nontolerant humans. Increasing the ethanol concentration to $100 \mathrm{~mm}$ caused a slightly greater reduction in average up-state amplitude and duration and eliminated spike activity during up states in most neurons tested. The decrease in up-state amplitude by ethanol was caused by a decrease in the membrane potential achieved during the up state rather than a depolarized down state. For example, in 10 neurons tested with $50 \mathrm{~mm}$ ethanol, the mean down-state membrane potential before ethanol exposure was $-71.1 \mathrm{mV}$ $( \pm 2.4)$ whereas during ethanol exposure it was $-69.2 \mathrm{mV}( \pm 2.2)$. Although the effect of ethanol on the number of spontaneous events (up states with or without firing) was not statistically significant, the number of events trended toward an increase at lower concentrations of ethanol (10-50 mM) and a decrease at $100 \mathrm{~mm}$ (data not shown). In addition, there was no significant correlation between the initial up-state amplitude, duration, or spiking during the control period and the degree of inhibition during ethanol exposure.

After washout of ethanol, persistent activity was occasionally enhanced relative to the pre-ethanol control period (Fig. 2, washout traces). This rebound increase in activity was rapid in onset and, when present, was usually associated with increases in upstate duration or spike firing rather than changes in up-state

A)

E)
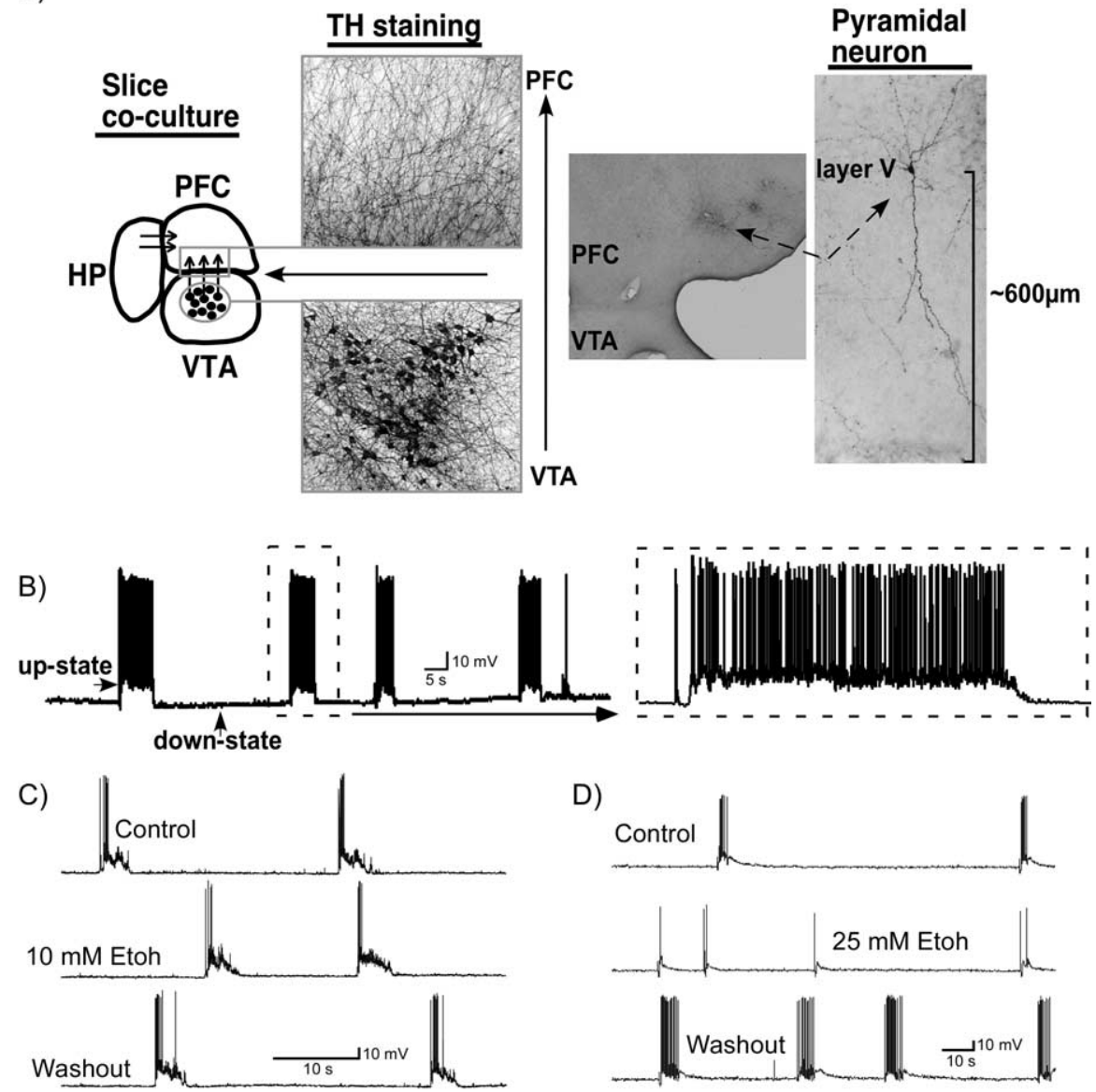

D)
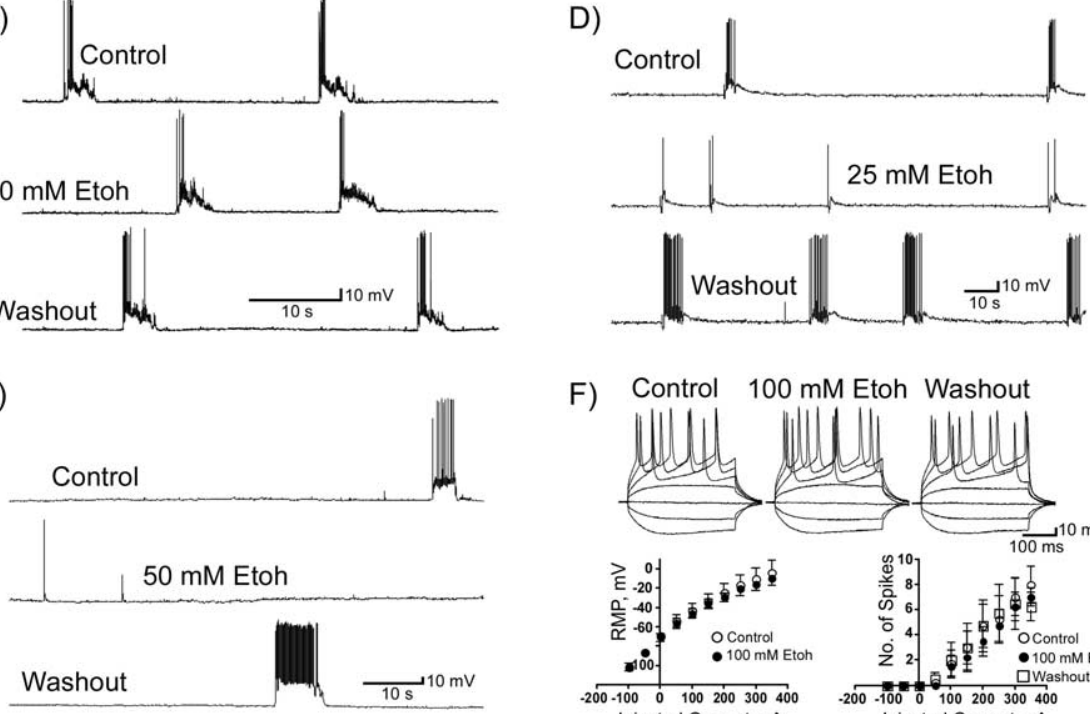

F) Control $100 \mathrm{mM}$ Etoh Washout
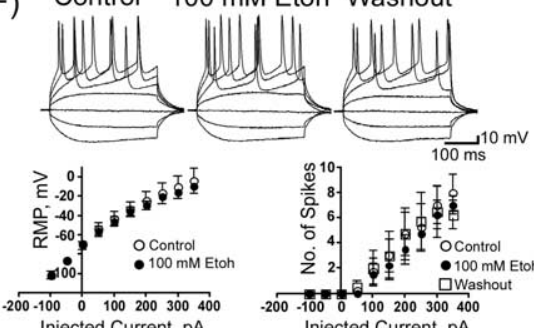

Injected Current, pA Injected Current, pA

Figure 2. Ethanol inhibits persistent activity in brain-slice cocultures. $\boldsymbol{A}$, Details of the slice coculture system. The diagram shows the orientation of brain slices in the coculture system used in the present study (HP, hippocampus). The middle panels show tyrosine-hydroxylase immunoreactivity (TH staining) with the bottom showing VTA cell bodies and top showing TH-positive fibers in the PFC portion of slice. The right panels show a biocytin-filled pyramidal neuron in the PFC portion of the slice coculture. $\boldsymbol{B}$, Representative trace (and expanded section showing one up-state period) showing example of bistability and persistent activity recorded from a single PFC pyramidal neuron under current-clamp mode. $\boldsymbol{C}-\boldsymbol{E}$, Representative traces showing the effects of ethanol $(10-50 \mathrm{~mm})$ on spontaneous persistent activity of single PFC pyramidal neurons. In each set of traces, the top trace is the control, the middle trace is in the presence of ethanol, and the bottom trace is after washout. $\boldsymbol{F}$, Effect of $100 \mathrm{~mm}$ ethanol on spike firing of PFC neurons induced by a series of current injections. The summary figures show the effects of $100 \mathrm{~mm}$ ethanol on resting membrane potential (left) and number of spikes (right) and are the mean \pm SEM from four neurons.

amplitude (Fig. 3, shaded bars). In addition, although the magnitude of the increase in up-state duration and spiking after ethanol washout was cell-dependent, it was most often observed after exposure to ethanol concentrations of $25 \mathrm{~mm}$ and higher.

\section{Effects of the NMDA antagonist APV}

In a previous study by Seamans et al. (2003), saturating concentrations of the NMDA receptor antagonist APV mostly eliminated up-state transitions and persistent activity. Ethanol also reduces NMDA receptor activity although at the concentrations 


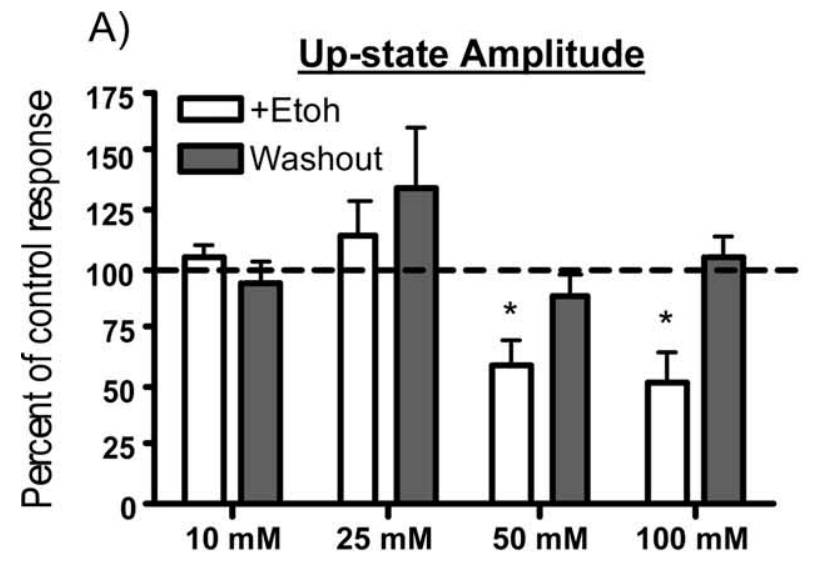

B)

\section{Up-state Duration}

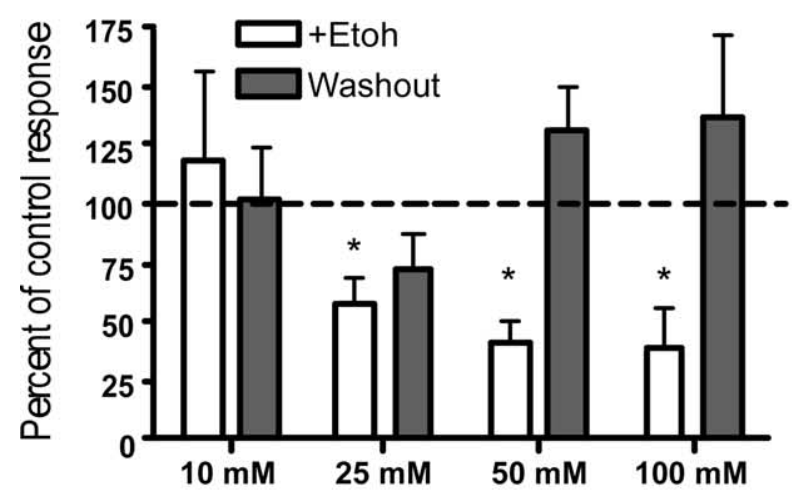

C) Spikes per Upstate

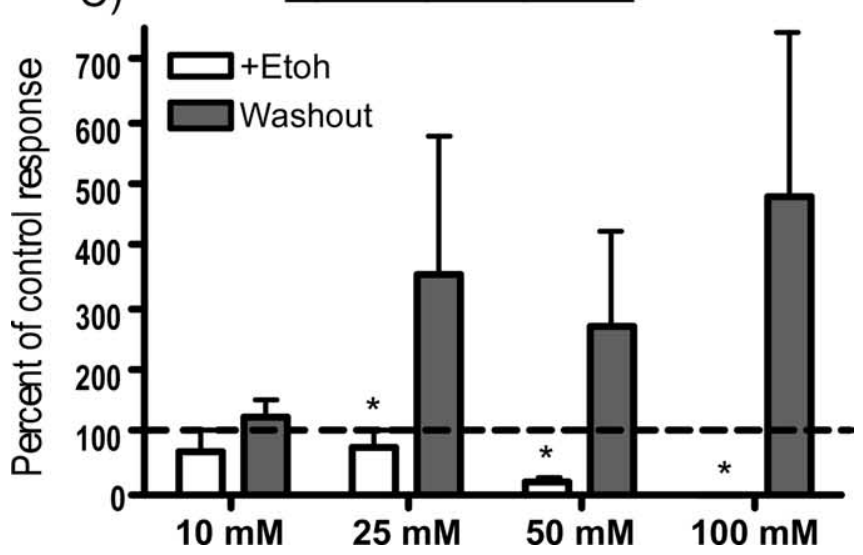

Figure 3. Effects of ethanol on individual components of spontaneous persistent activity of PFC neurons. $\boldsymbol{A}-\boldsymbol{C}$, Summary graphs show changes in up-state amplitude $(\boldsymbol{A})$, up-state duration $(\boldsymbol{B})$, and spike activity $(\boldsymbol{C})$ during (open bars) and after (shaded bars) exposure to ethanol (Etoh; $10-100 \mathrm{~mm}$ ). Data represent the mean ( $\pm \mathrm{SEM} ; n=4-10$ neurons per concentration) and are expressed as a percentage of the predrug control value. *Significantly different from corresponding control value ( $p<0.05$, ANOVA with repeated measures and post hoc testing).

used in the present study $(10-100 \mathrm{~mm})$ this inhibition would be expected to be incomplete (Jin and Woodward, 2006). To further investigate the involvement of NMDA receptors in persistent activity of PFC neurons, slice cocultures were treated with a low concentration of APV $(5 \mu \mathrm{M})$. This concentration only partially blocks NMDA receptor currents evoked by saturating concentrations of agonist and, thus, should more accurately reflect the low efficacy of ethanol as an NMDA antagonist (Blevins et al., 1995).
A)

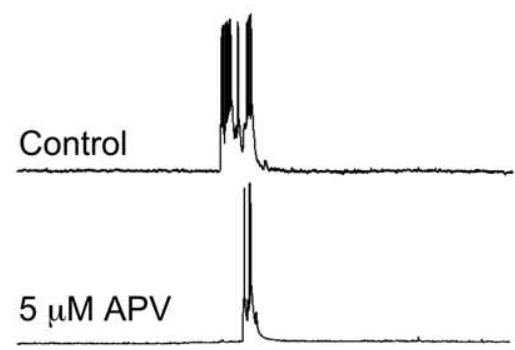

B)
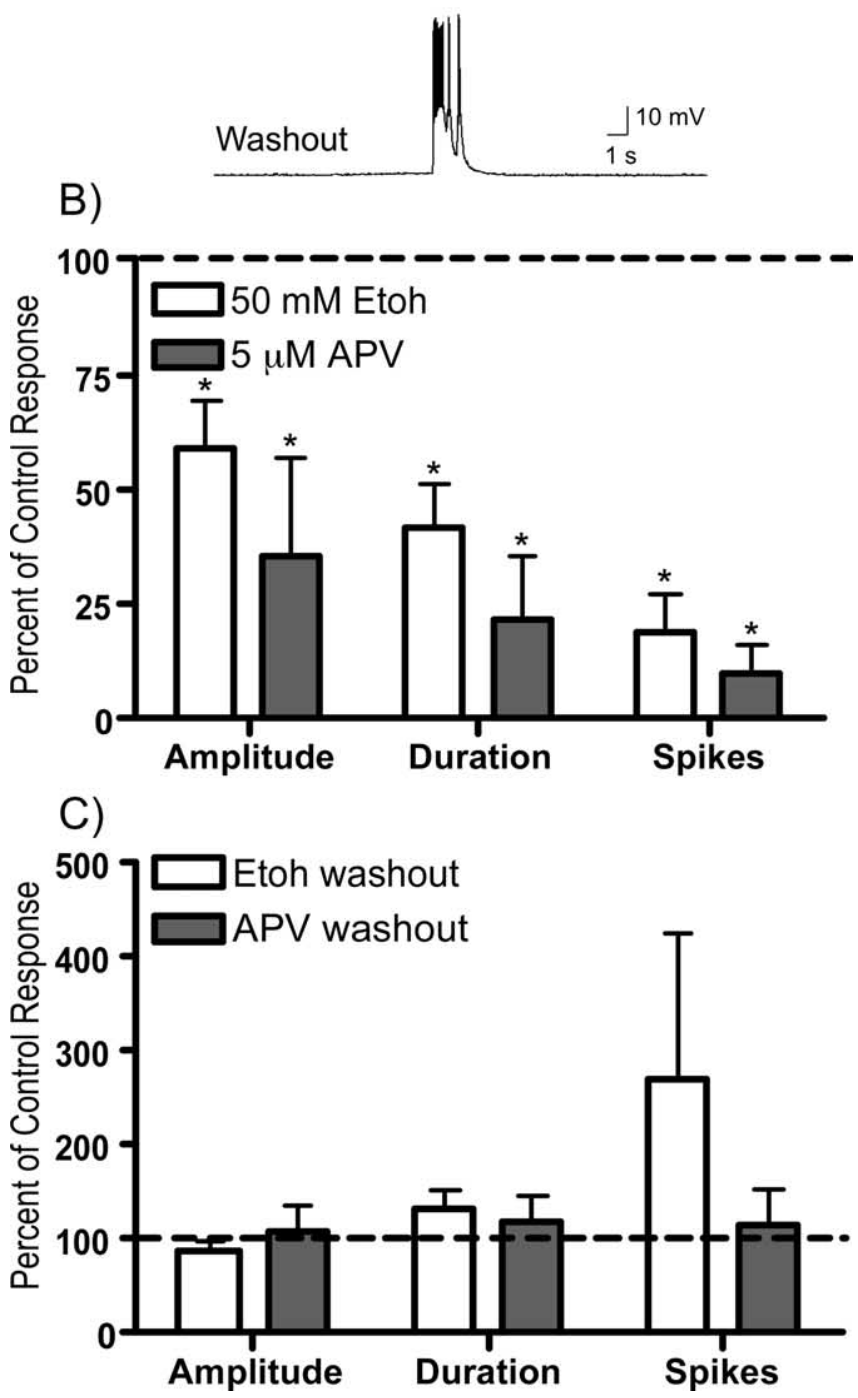

Figure 4. The NMDA antagonist APV reduces spontaneous persistent activity of PFC neurons in slice cocultures. $\boldsymbol{A}$, Representative traces showing persistent activity of a single PFC pyramidal neuron before, during, and after exposure to $5 \mu \mathrm{m}$ APV. $B, C$, Summary graphs show up-state amplitude, duration, and spike activity during $(\boldsymbol{B})$ and after ( $\boldsymbol{C}$ exposure to APV (shaded bars). In $\boldsymbol{B}$ and $\boldsymbol{C}$, the effects of $50 \mathrm{~mm}$ ethanol (Etoh) on persistent activity are shown for comparison (open bars; data taken from Fig. 3). Data represent the mean ( \pm SEM; $n=5$ for APV and 10 for $50 \mathrm{~mm}$ Etoh) and are expressed as a percentage of the corresponding predrug control value. * Significantly different from corresponding control value ( $p<0.05$, ANOVA with repeated measures and post hoc testing).

As shown in Figure 4, $5 \mu \mathrm{M}$ APV significantly reduced up-state amplitude, duration, and spike activity. For comparison, the effects of $50 \mathrm{~mm}$ ethanol on these parameters (taken from the data shown Fig. 3) are also shown. Although APV produced a slightly greater inhibition of persistent activity than $50 \mathrm{~mm}$ ethanol, no obvious rebound excitation was observed after washout. 
Ethanol, persistent activity, and dopamine

\section{D1 antagonist studies}

In vivo, the mesocorticolimbic dopamine system is a crucial component of the addiction neurocircuitry and dopaminergic fibers from the VTA make synaptic contact with deep-layer cortical pyramidal neurons (Berger et al., 1991). Dopamine has complex actions on both glutamatergic and GABAergic neurons within the prefrontal cortex and acts via multiple signaling pathways to modulate their excitability. D1 receptors are thought to be especially important in regulating PFC output and are highly expressed on deeplayer pyramidal neurons (for review, see Seamans and Yang, 2004). To investigate the potential involvement of D1 dopamine receptors in modulating the effects of ethanol on persistent activity, slices were exposed to the D1 antagonist $R(+)$ 7-chloro-8-hydroxy-3-methyl-1-phenyl2,3,4,5-tetrahydro-1 H-3-benzazepine hydrochloride (SCH23390) alone or in combination with $50 \mathrm{~mm}$ ethanol. When administered alone, SCH23390 (10 $\mu \mathrm{M})$ did not significantly alter persistent activity (Fig. $5 A, C$ ) suggesting that at this concentration, SCH23390 had no direct effect on NMDA receptors (Cui et al., 2006). In a separate group of neurons, coperfusion of slice cocultures with SCH23390 and 50 $\mathrm{mm}$ ethanol produced a marked inhibition of persistent activity that was greater than that seen in neurons exposed to $50 \mathrm{~mm}$ ethanol alone (compare Figs. 3, $5 B, D)$. After washout of ethanol and SCH23390, average up-state duration and spike activity were greater than predrug control values whereas up-state amplitude showed little change (Fig. 5D).

\section{VTA stimulation}

In vivo, VTA dopamine neurons normally fire at a low frequency $(1-5 \mathrm{~Hz})$ whereas burst firing often accompanies presentation of relevant or novel stimuli (Schultz et al., 1997; Hyland et al., 2002). VTA stimulation evokes a glutamatergic EPSP in the PFC both in vitro and in vivo and can evoke up states and persistent activity in PFC neurons (Seamans et al., 2003; Lavin et al., 2005) In the present study, a stimulating electrode was placed in the VTA portion of the slice coculture and trains of stimuli ( 5 pulses at $20 \mathrm{~Hz}$ ) were applied at regular intervals while recording from single PFC neurons. The amount of current delivered to the stimulating electrode was initially adjusted to yield reproducible responses in each recorded PFC neuron.
A)

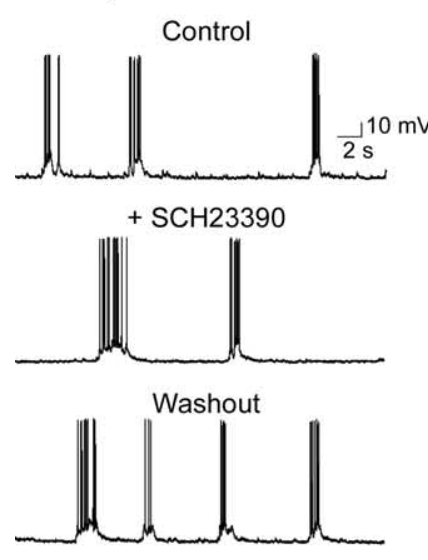

B)

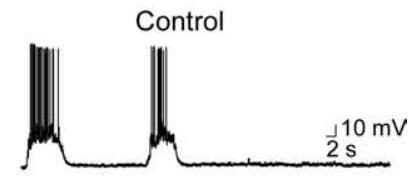

$50 \mathrm{mM}$ Etoh + SCH23390

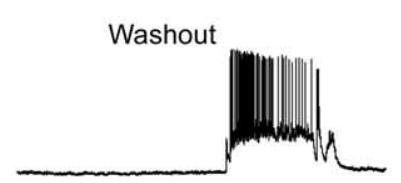

C)
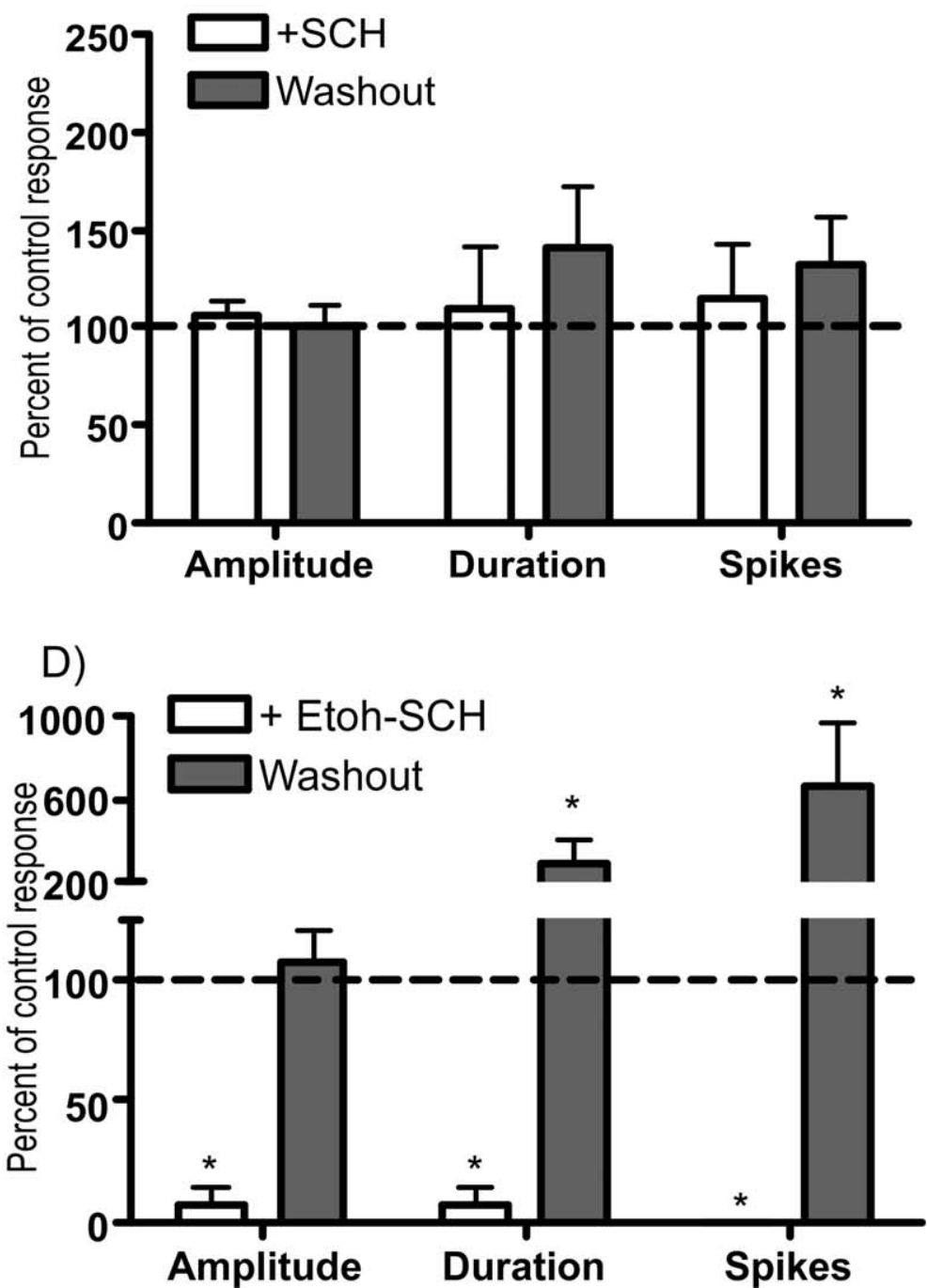

Figure 5. The D1 receptor antagonist SCH23390 enhances ethanol inhibition of spontaneous persistent activity. $\boldsymbol{A}, \boldsymbol{B}$, Representative traces of spontaneous persistent activity recorded from single PFC neurons in the presence of SCH23390 (SCH) alone (10 $\mu \mathrm{m} ; \boldsymbol{A})$ or SCH23390 (10 $\mu \mathrm{m})$ plus $50 \mathrm{~mm}$ ethanol (Etoh; $\boldsymbol{B})$. C, D, Summary graphs show up-state amplitude, duration, and spike activity during (open bars) and after (shaded bars) exposure to $\mathrm{SCH} 23990$ (C) or SCH23390 plus ethanol (D). Data represent the mean ( \pm SEM; $n=12$ for SCH alone and 5 for SCH plus Etoh) and are expressed as a percentage of the corresponding predrug control value. * Significantly different from corresponding control value $(p<0.05$, ANOVA with repeated measures with post hoc testing). 
A)
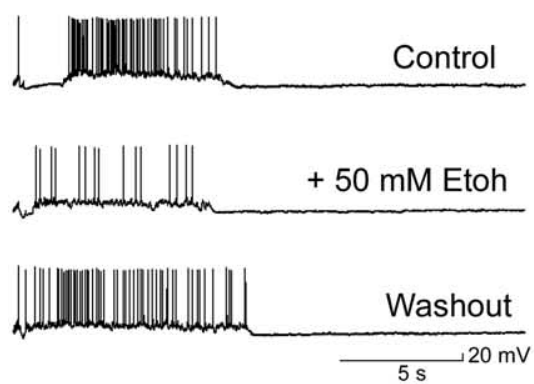

B)
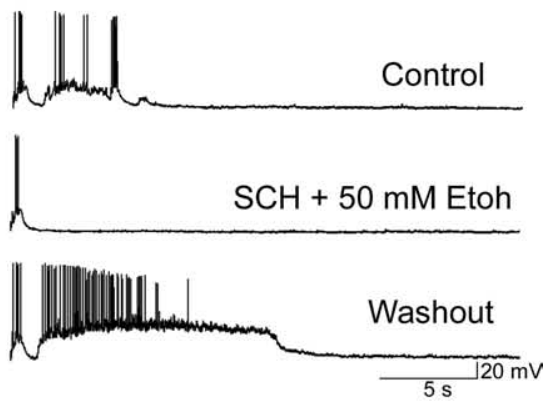

C) VTA Evoked-50 mM Etoh
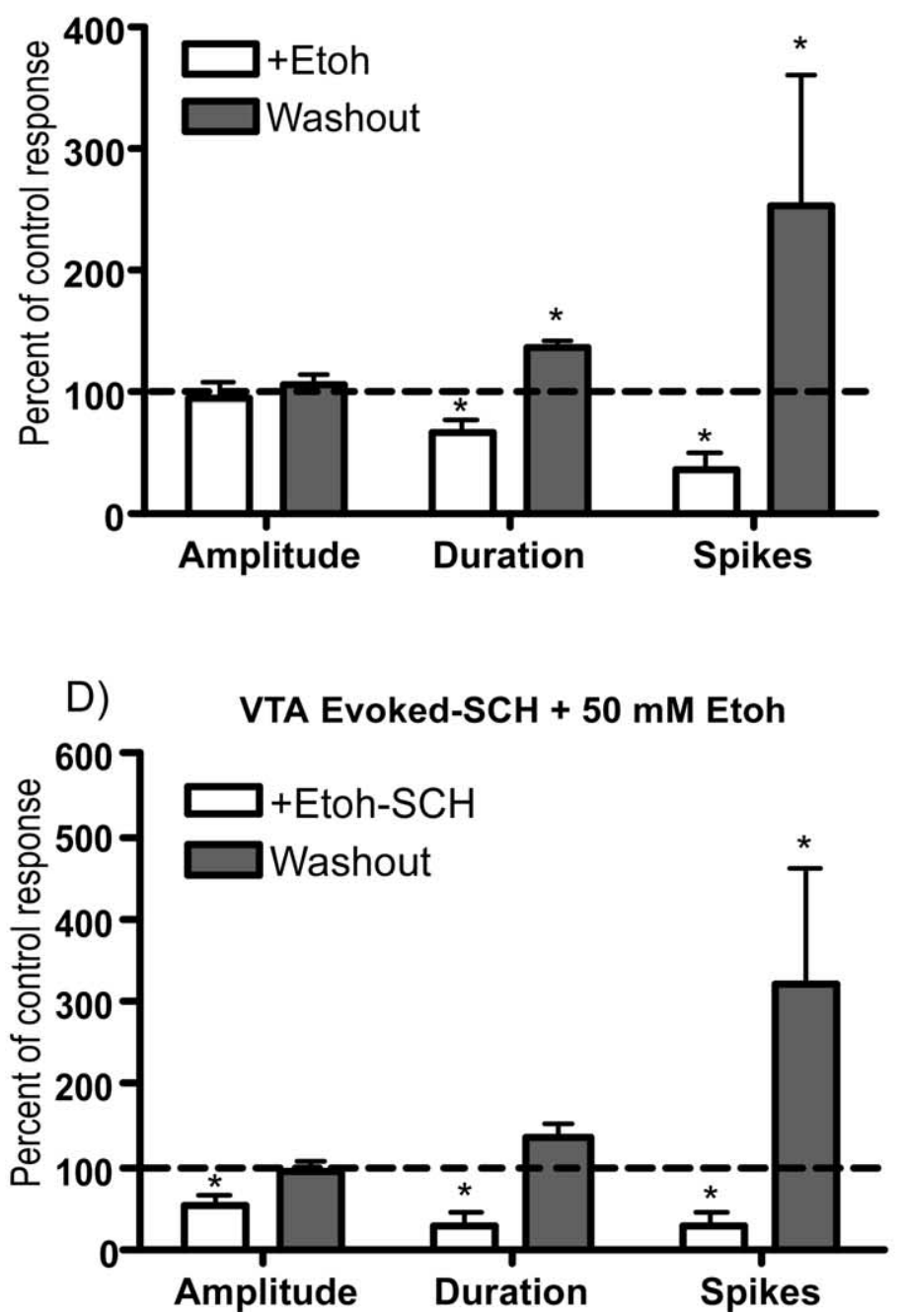

Figure 6. Effects of ethanol on persistent activity induced by VTA stimulation. $\boldsymbol{A}, \boldsymbol{B}$, Traces show VTA-evoked (5 pulse train, 20 $\mathrm{Hz}$ ) persistent activity of single PFC neurons before, during, and after exposure to $50 \mathrm{~mm}$ ethanol $(\boldsymbol{A})$ or the combination of $50 \mathrm{~mm}$ ethanol and $10 \mu \mathrm{M}$ SCH23390 (B). C, D, Summary graphs below show effects of ethanol (C) or ethanol plus SCH23390 (D) on up-state amplitude, duration, and spike activity during (open bars) or after (shaded bars) washout of the test solution. Data represent the mean ( \pm SEM; $n=8$ VTA plus Etoh and 9 for VTA plus Etoh plus $\mathrm{SCH}$ ) and are expressed as a percentage of the corresponding predrug control value. *Significantly different from corresponding control value $(p<0.05$, ANOVA with repeated measures with post hoc testing).

Burst stimulation of the VTA induced up-state transitions and spike firing in PFC neurons (Fig. 6A). VTA-induced persistent activity was measured in 63 neurons in the absence and presence of ethanol. The average membrane potential during down states in these neurons was $-74.2 \mathrm{mV}( \pm 0.9)$ whereas during up states it was $-57.6 \mathrm{mV}$ $( \pm 1.4)$. VTA-evoked up states had a mean amplitude of $16.6 \mathrm{mV}( \pm 1.1)$ and an average duration of $4.8 \mathrm{~s}( \pm 0.3)$. The average number of spikes during each VTAevoked up state was $19.4( \pm 3.5)$, with a mean frequency of firing of $3.9 \mathrm{~Hz}( \pm 0.6)$.

Ethanol also reduced persistent activity of PFC neurons after VTA stimulation (Fig. $6 A, C$ ), although the magnitude of this inhibition was generally smaller than that observed for spontaneous activity. As shown in Figure 3, $50 \mathrm{~mm}$ ethanol inhibited the amplitude and duration of spontaneous up states by $\sim 40$ and $60 \%$ of their corresponding control values. However, as shown in Figure 6C, during VTA stimulation, this same concentration of ethanol reduced up-state amplitude by $\sim 10 \%$ and up-state duration by $34 \%$. A similar attenuation in the ethanol inhibition of VTA-stimulated activity was observed with other concentrations of ethanol (data not shown). After washout of the ethanolcontaining solution, persistent activity evoked by VTA stimulation was often enhanced, although again the magnitude of this effect was cell-dependent (Fig. 6C, shaded bars). To determine the effect of D1 receptors on the ethanol inhibition of persistent activity induced by VTA stimulation, additional recordings were performed in the presence of the D1 antagonist SCH23390. In control studies, exposure of slice cultures to SCH23390 $(10 \mu \mathrm{M})$ alone produced no significant effect on the mean ( \pm SEM; $n=8$ ) amplitude $(104.5 \pm 7.4 \%)$, duration (117.7 \pm $23.7 \%)$, or spike-firing $(109.7 \pm 24.2 \%)$ of PFC neurons after VTA stimulation. In a separate group of neurons, persistent activity induced by VTA stimulation was markedly reduced during simultaneous application of SCH23390 $(10 \mu \mathrm{M})$ and 50 mm ethanol (Fig. 6B,D). Under these conditions, up-state amplitude was reduced by $\sim 45 \%$ whereas up-state duration and number of spikes were inhibited by nearly $70 \%$. After washout of ethanol and SCH23390, there was again evidence of a variable increase in persistent activity similar to that observed in the absence of SHC23390 (Fig. 6D).

Ethanol and VTA dopamine neuron firing Ethanol enhances the spontaneous firing of VTA dopamine neurons from both rats and mice (Brodie et al., 1990; Okamoto et al., 2006). To determine whether ethanol causes a similar effect in slice cocultures, the spontaneous firing of VTA dopamine neurons was monitored by cell-attached recordings during application of ethanol. In these experiments, 
cultures were prepared from transgenic mice that express GFP under the control of a tyrosine hydroxylase promoter (Matsushita et al., 2002). Clusters of GFPpositive neurons were easily identified in the midbrain section of the coculture and PFC neurons in these cultures showed both spontaneous and evoked up states (Fig. $7 A, B$ ). The mean ( $\pm \mathrm{SEM} ; n=17$ ) firing rate of GFP-positive midbrain neurons under control conditions was $0.88 \pm$ $0.13 \mathrm{~Hz}$. Ethanol, at concentrations of 25 or $100 \mathrm{~mm}$ appeared to slightly enhance the spontaneous firing rate of midbrain dopamine neurons but this effect was variable and overall was not statistically significant (Fig. 7C,D).

\section{Persistent activity in}

PFC/hippocampal cultures

To further investigate the role of dopamine in the ethanol modulation of persistent activity, a series of recordings were performed in cultures containing only the PFC and hippocampal slices. Similar to triple-slice cultures, PFC neurons in cultures lacking DA neurons showed spontaneous episodes of persistent activity (Fig. $8 A$ ). The mean ( \pm SEM, $n=5$ ) amplitude, duration, and number of spikes per up state in these neurons were $17.4 \pm 3.1 \mathrm{mV}$, $2.0 \pm 0.4 \mathrm{~s}$, and $15.3 \pm 5.8$; respectively. Ethanol (50 mM) inhibited up-state amplitude by $\sim 30 \%$ and up-state duration and spiking were reduced by $70-75 \%$; respectively. After washout of the ethanol containing solution, up-state amplitude was similar to that of control values whereas up-state duration and number of spikes per up state were significantly increased relative to the control values.

\section{Discussion}

The results of this study demonstrate that ethanol markedly affects the activity of PFC neurons. Ethanol inhibited persistent activity and spike firing in the slice cocultures and reduced PFC firing in vivo. The concentrations of ethanol that produced these effects $(17-100 \mathrm{~mm} ; \sim 0.08-0.4 \%$ blood alcohol concentration) are similar to those that alter PFC-mediated behaviors including working memory, error detection (Melchior et al., 1993; Givens and McMahon, 1997; Ridderinkhof et al., 2002; Rossetti et al., 2002), and EEG responses after stimulation of the frontal cortex in humans (Kahkonen et al., 2003). Ethanol's inhibition of persistent activity in the slice cocultures appeared to involve synaptic sites of action, as even high concentrations of ethanol had little effect on firing evoked by direct current injection.

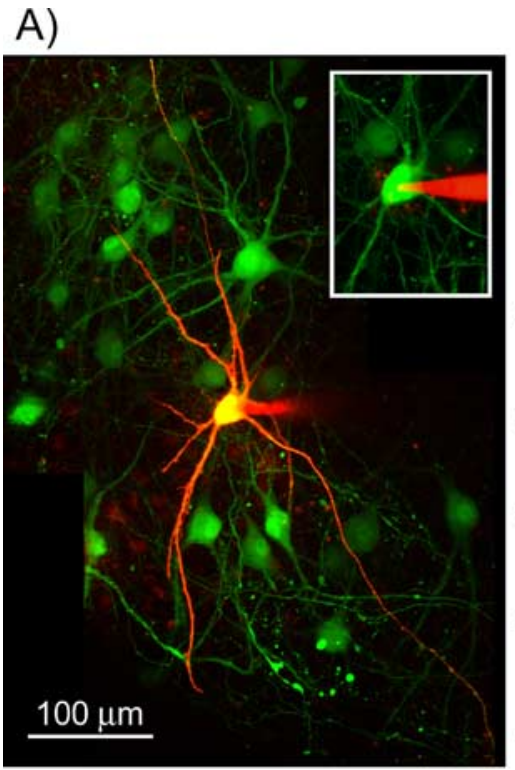

B)

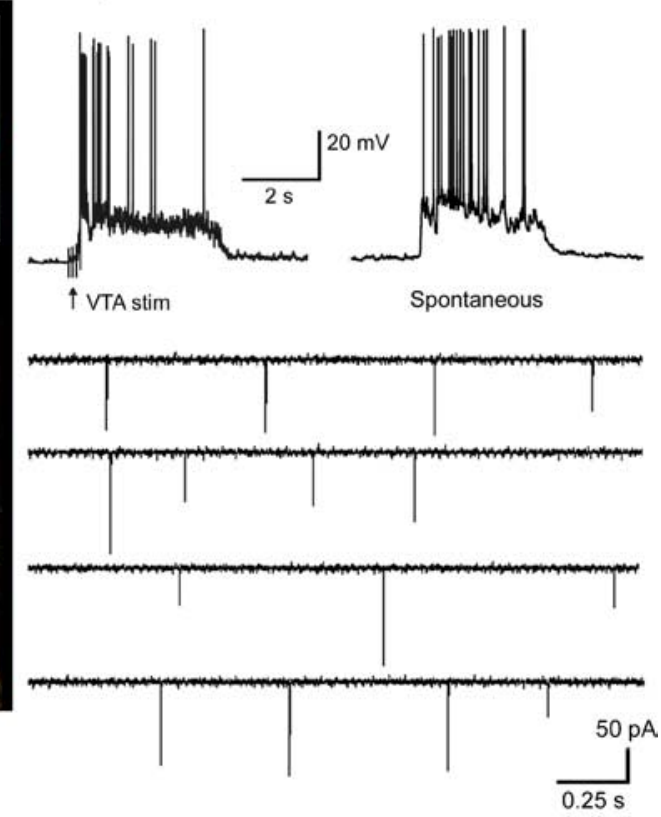

C)
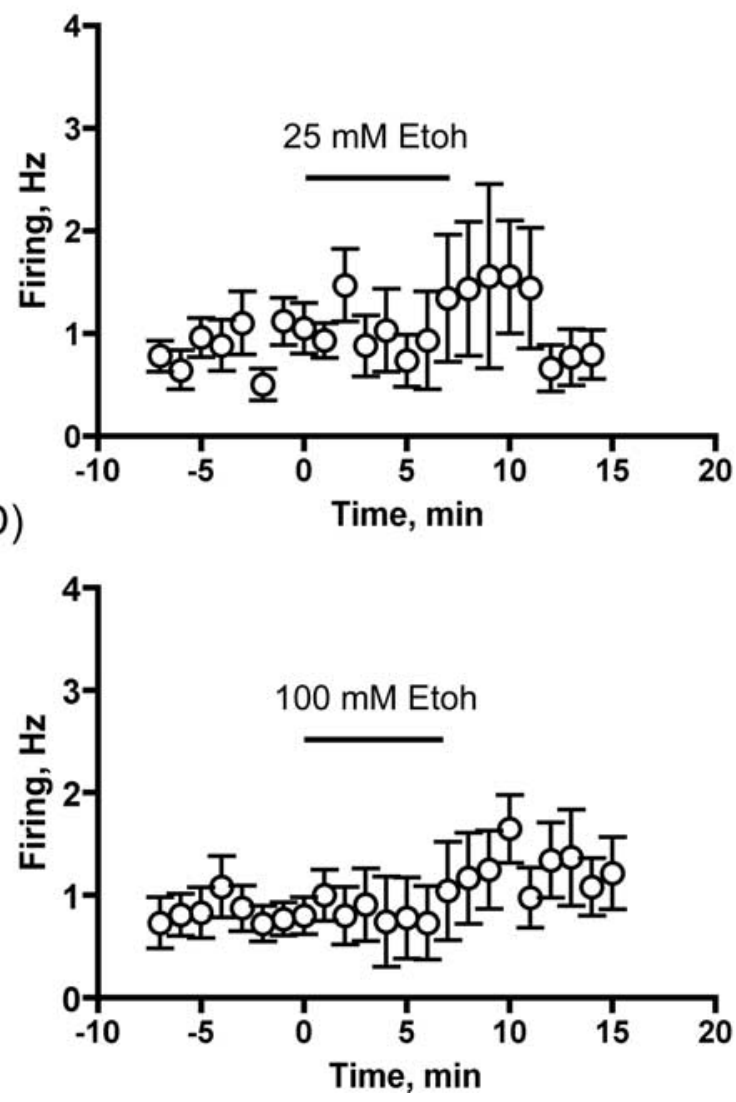

Figure 7. Effects of ethanol on the spontaneous firing of midbrain dopamine neurons in the slice cocultures. $\boldsymbol{A}$, Midbrain portion of a slice coculture prepared from transgenic mice in which GFP expression is driven by a tyrosine-hydroxylase promoter. The neuron in the center was filled with Alexa 594 dye after recording of spontaneous firing activity. The inset shows the same neuron during cell-attached recording and before obtaining whole-cell access. $\boldsymbol{B}$, Top two traces show VTA-evoked (left) and spontaneous (right) up states in PFC neurons from TH-GFP slice cocultures. The bottom traces show spontaneous firing of a single midbrain dopamine neuron. $C, D$, Summary figures show the average firing rate of dopamine neurons in the absence and presence (indicated by the horizontal bar) of $25 \mathrm{~mm}(\boldsymbol{C})$ or $100 \mathrm{~mm}(\boldsymbol{D})$ ethanol. Data are the mean ( \pm SEM) from eight to nine different neurons for each ethanol concentration. 
A)

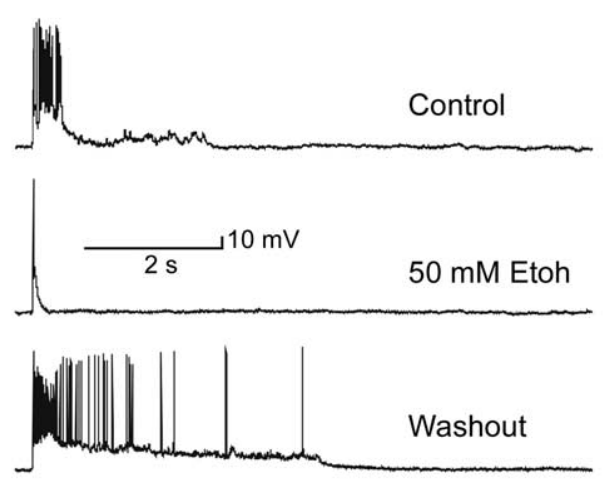

B)

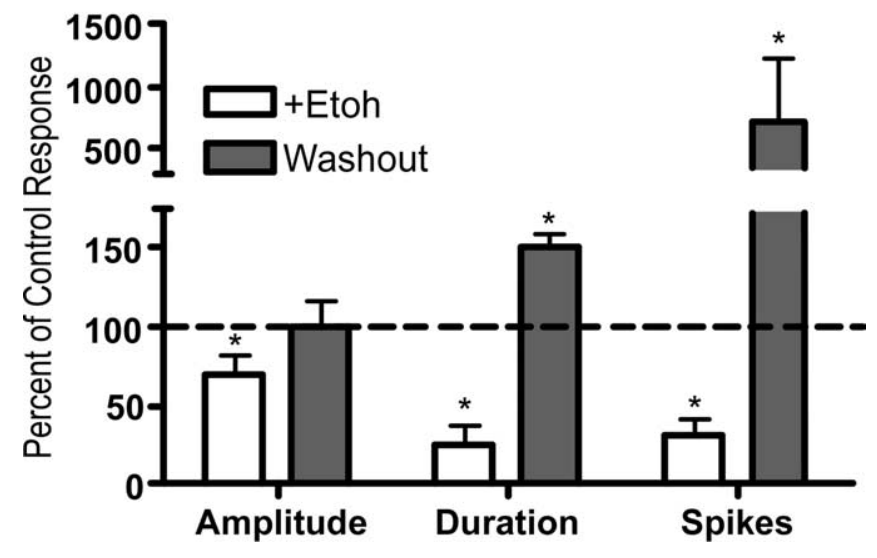

Figure 8. Effects of ethanol on spontaneous persistent activity of PFC neurons in slice cultures lacking midbrain dopamine neurons. $\boldsymbol{A}$, Representative traces of persistent activity in a single PFC neuron before, during, and after exposure to $50 \mathrm{~mm}$ ethanol. $\boldsymbol{B}$, Summary graph showing effect of ethanol on up-state amplitude, duration, and spike activity during (open bars) or after (shaded bars) washout of the ethanol containing solution. Data represent the mean ( $\pm S E M ; n=5$ ) and are expressed as a percentage of the corresponding predrug control value. *Significantly different from corresponding control value ( $p<0.05$, ANOVA with repeated measures with post hoc testing).

\section{Ethanol modulation of PFC persistent activity}

The cellular mechanisms that regulate persistent activity of PFC neurons are complex and require coordinated glutamatergic and GABAergic synaptic inputs. Perfusion of slice cocultures with antagonists of non-NMDA or NMDA receptors inhibits persistent activity whereas direct activation of $\mathrm{GABA}_{\mathrm{A}}$ receptors clamps the membrane potential below the threshold needed for firing (Seamans et al., 2003). Inhibition of persistent activity could thus arise if ethanol inhibited excitatory glutamatergic activity or enhanced GABAergic tone or both. To our knowledge, the direct effect of ethanol on synaptic glutamatergic and GABAergic transmission in deep-layer neurons of the prefrontal cortex has not been reported. However, results from studies from our laboratory show that, in acute slices, synaptic NMDA currents from deep-layer PFC neurons are reliably inhibited by moderate (44 $\mathrm{mM}$ ) concentrations of ethanol whereas those generated by AMPA or $\mathrm{GABA}_{\mathrm{A}}$ receptors are mostly unaffected (our unpublished observations). These findings are generally consistent with other studies showing that ethanol has little effect on most AMPA-mediated EPSCs (Lovinger et al., 1989; Weiner et al., 1999) (but see Mameli et al., 2005; Carta et al., 2006) and has variable effects on GABA-mediated currents (for review, see Weiner and Valenzuela, 2006). Importantly, NMDA-dependent response processes are consistently reported to be inhibited by ethanol including those from hippocampus (Lovinger et al., 1990), posterior cingulate (Li et al., 2002), nucleus accumbens (Nie et al., 1994), and amygdala (Roberto et al., 2004). It should be noted that the ethanol inhibition of NMDA receptors is incomplete even at concentrations associated with severe behavioral impairment. For example, in a study of 32 different recombinant NMDA receptors, $100 \mathrm{~mm}$ ethanol inhibited currents by $18-55 \%$, depending on the subunits expressed (Jin and Woodward, 2006). Whether this range of inhibition is sufficient to reduce persistent activity of PFC neurons is not completely known. However, computational modeling studies show that NMDA currents are critical in maintaining persistent activity and that even modest reductions in NMDA receptor input significantly inhibit up states (Wang, 1999; Durstewitz et al., 2000; Wolf et al., 2005). This was verified in the present study as activity was significantly reduced by the NMDA antagonist APV at a concentration predicted to only partially inhibit synaptic NMDA receptor activity. Although these findings do not rule out an important role for other processes, they suggest that NMDA receptors are likely targets for ethanol's effect of persistent activity.

\section{Dopamine modulation of ethanol inhibition of persistent activity}

The degree of ethanol inhibition of persistent activity was affected by conditions designed to alter dopamine receptor-mediated signaling. For example, inhibition was enhanced in the presence of the D1 antagonist SCH23390 whereas VTA stimulated activity was less affected. The mechanism(s) underlying these effects are likely to be complex and involve multiple pathways given the wide range of action of dopamine on neuronal function (Seamans and Yang, 2004). Interestingly, D1 receptor agonists have been reported to decrease the ethanol inhibition of NMDA EPSCs in nucleus accumbens neurons (Maldve et al., 2002; Zhang et al., 2005). This effect was correlated with increased phosphorylation of the NR1 PKA (protein kinase A) site as measured by a phosphospecific antibody, suggesting that this site may directly regulate the ethanol sensitivity of NMDA receptors. Although this hypothesis was not supported by results of a subsequent study (Xu and Woodward, 2006), D1-mediated changes in network excitability could reduce ethanol inhibition of persistent activity without altering the acute ethanol sensitivity of NMDA receptors. For example, AMPA and NMDA receptor function are enhanced after D1 receptor activation through changes in channel kinetics and/or increases in forward trafficking and membrane expression of these receptors (Flores-Hernandez et al., 2002; Mangiavacchi and Wolf, 2004; Wirkner et al., 2004; Sun et al., 2005). D1-mediated potentiation of ionotropic glutamate receptor signaling may enhance excitatory drive of PFC networks to levels greater than that needed to initiate and maintain persistent activity. Pharmacological blockade of this signaling pathway would remove this modulatory influence and make the network more susceptible to ethanol-induced disruption.

\section{Ethanol and rebound excitation after washout}

A rebound increase in persistent activity of PFC neurons was often observed after washout of ethanol and was associated with changes in up-state duration and spiking, as up-state amplitude was not affected. Although the mechanism underlying this effect is unknown, NMDA receptors may be involved as these receptors are critical in maintaining the sustained depolarization underlying up states (Durstewitz et al., 2000; Seamans et al., 2003). Two pathways that could lead to enhanced NMDA receptor drive in- 
clude ethanol-induced increases in D1 signaling and increased tyrosine phosphorylation of NMDA receptors. Ethanol may increase dopamine signaling through an enhancement of VTA dopamine neuron firing, leading to increased excitability of PFC neurons. Two observations reduce the chances that this action alone drives increased activity after ethanol washout. First, although ethanol does enhance DA neuron firing (Gessa et al., 1985; Appel et al., 2003; Okamoto et al., 2006), the magnitude of this change is relatively small, on the order of $15-20 \%$. We found evidence for similar small changes in DA neuron firing in the present study, although these did not reach statistical significance. Second, and perhaps more importantly, slice cultures containing only the PFC and hippocampus still showed increases in up-state duration and spike firing after ethanol exposure, suggesting that dopamine is not required for this action. Similar ethanol-induced increases in NMDA-dependent responses have been reported in preparations of locus ceruleus, hippocampus, or spinal cord neurons, where dopamine cell bodies are also absent (Morrisett, 1994; Poelchen et al., 1997; Li and Kendig, 2003; Yaka et al., 2003). The rebound effect in these neurons was associated with increases in the tyrosine phosphorylation of NR2 NMDA receptor subunits and was blocked by inhibitors of Src-family tyrosine kinases (Li and Kendig, 2003; Yaka et al., 2003). These kinases increase the activity of both recombinant and native NMDA receptors via enhanced insertion and reduced internalization of surface receptors (Wang and Salter, 1994; Chen and Leonard, 1996; Skeberdis et al., 2001; Vissel et al., 2001; Dunah et al., 2004). The pathway linking ethanol to enhanced tyrosine phosphorylation of NMDA receptors is not completely known, but may involve dissociation of regulatory proteins such as Rack-1 that bind to and reduce the activity of Fyn and other Src-family tyrosine kinases (Yaka et al., 2002).

Whether PFC neurons in vivo show a similar rebound in activity is currently not known. Unlike the situation with the sliceculture system in which solution exchange is rapid, removal of ethanol in vivo is slow because of the zero-order kinetics of alcohol metabolism. Results from the in vivo recordings of PFC spike activity reflect this difference in pharmacokinetics because firing rates after ethanol administration were suppressed for prolonged periods. However, in nonanesthetized animals and human subjects, rapid tolerance to some effects of ethanol does occur, suggesting adaptation of neurons in certain brain regions during sustained exposure to behaviorally relevant concentrations of ethanol (Schwarz et al., 1981; Miyakawa et al., 1997; Chandler et al., 1998; Fadda and Rossetti, 1998). Although highly speculative, a similar recovery in the activity of PFC neurons during in vivo ethanol exposure could represent a form of acute functional tolerance that might limit ethanol-induced impairment of processes subserved by these neurons. Differences in the extent and/or rate of this compensation could contribute to differences in the susceptibility of individuals to ethanol-induced changes in prefrontal function that may contribute to the development of alcohol addiction.

\section{Functional implications}

The results of this study provide the first direct evidence that ethanol disrupts complex patterns of persistent activity in deeplayer pyramidal neurons of the PFC. Given the importance of this area in planning and decision-making, these effects may underlie some of the deficits in cognition, working memory, and executive function observed after ethanol intake. This impairment in prefrontal processing may also reduce performance and error monitoring during complex tasks and diminish one's ability to inhibit deleterious behaviors including control over alcohol drinking. Sustained alterations or adaptations in prefrontal function resulting from chronic drug and alcohol use could contribute to the loss of inhibitory control over drug taking that characterizes alcoholism and drug addiction. These results thus provide an important foundation from which to explore the mechanisms by which alcohol leads to these changes.

\section{References}

Appel SB, Liu Z, McElvain MA, Brodie MS (2003) Ethanol excitation of dopaminergic ventral tegmental area neurons is blocked by quinidine. J Pharmacol Exp Ther 306:437-446.

Berger B, Gaspar P, Verney C (1991) Dopaminergic innervation of the cerebral cortex: unexpected differences between rodents and primates. Trends Neurosci 14:21-27.

Blevins T, Mirshahi T, Woodward JJ (1995) Increased agonist and antagonist sensitivity of $N$-methyl-D-aspartate stimulated calcium flux in cultured neurons following chronic ethanol exposure. Neurosci Lett 200:214-218

Brodie MS, Shefner SA, Dunwiddie TV (1990) Ethanol increases the firing rate of dopamine neurons of the rat ventral tegmental area in vitro. Brain Res 508:65-69.

Carpenter-Hyland EP, Woodward JJ, Chandler LJ (2004) Chronic ethanol induces synaptic but not extrasynaptic targeting of NMDA receptors. J Neurosci 24:7859-7868.

Carta M, Mameli M, Valenzuela CF (2006) Alcohol potently modulates climbing fiber $\rightarrow$ Purkinje neuron synapses: role of metabotropic glutamate receptors. J Neurosci 26:1906-1912.

Chandler LJ, Harris RA, Crews FT (1998) Ethanol tolerance and synaptic plasticity. Trends Pharmacol Sci 19:491-495.

Chen SJ, Leonard JP (1996) Protein tyrosine kinase-mediated potentiation of currents from cloned NMDA receptors. J Neurochem 67:194-200.

Cui C, Xu M, Atzori M (2006) Voltage-dependent block of N-methyl-Daspartate receptors by dopamine D1 receptor ligands. Mol Pharmacol 70:1761-1770.

Dunah AW, Sirianni AC, Fienberg AA, Bastia E, Schwarzschild MA, Standaert DG (2004) Dopamine D1-dependent trafficking of striatal N-methylD-aspartate glutamate receptors requires Fyn protein tyrosine kinase but not DARPP-32. Mol Pharmacol 65:121-129.

Durstewitz D, Seamans JK, Sejnowski TJ (2000) Neurocomputational models of working memory. Nat Neurosci 3 [Suppl]:1184-1191.

Fadda F, Rossetti ZL (1998) Chronic ethanol consumption: from neuroadaptation to neurodegeneration. Prog Neurobiol 56:385-431.

Flores-Hernandez J, Cepeda C, Hernandez-Echeagaray E, Calvert CR, Jokel ES, Fienberg AA, Greengard P, Levine MS (2002) Dopamine enhancement of NMDA currents in dissociated medium-sized striatal neurons: role of D1 receptors and DARPP-32. J Neurophysiol 88:3010-3020.

Franke H, Schelhorn N, Illes P (2003) Dopaminergic neurons develop axonal projections to their target areas in organotypic co-cultures of the ventral mesencephalon and the striatum/prefrontal cortex. Neurochem Int 42:431-439.

Gessa GL, Muntoni F, Collu M, Vargiu L, Mereu G (1985) Low doses of ethanol activate dopaminergic neurons in the ventral tegmental area. Brain Res 348:201-203.

Givens B, McMahon K (1997) Effects of ethanol on nonspatial working memory and attention in rats. Behav Neurosci 111:275-282.

Goldman-Rakic PS (1999) The physiological approach: functional architecture of working memory and disordered cognition in schizophrenia. Biol Psychiatry 46:650-661.

Hyland BI, Reynolds JN, Hay J, Perk CG, Miller R (2002) Firing modes of midbrain dopamine cells in the freely moving rat. Neuroscience 114:475-492.

Jin C, Woodward JJ (2006) Effects of 8 different NR1 splice variants on the ethanol inhibition of recombinant NMDA receptors. Alcohol Clin Exp Res 30:673-679.

Kahkonen S, Wilenius J, Nikulin VV, Ollikainen M, Ilmoniemi RJ (2003) Alcohol reduces prefrontal cortical excitability in humans: a combined TMS and EEG study. Neuropsychopharmacology 28:747-754.

Kalivas PW, Volkow N, Seamans J (2005) Unmanageable motivation in addiction: a pathology in prefrontal-accumbens glutamate transmission. Neuron 45:647-650. 
Kamarajan C, Porjesz B, Jones KA, Choi K, Chorlian DB, Padmanabhapillai A, Rangaswamy M, Stimus AT, Begleiter H (2004) The role of brain oscillations as functional correlates of cognitive systems: a study of frontal inhibitory control in alcoholism. Int J Psychophysiol 51:155-180.

Lavin A, Nogueira L, Lapish CC, Wightman RM, Phillips PE, Seamans JK (2005) Mesocortical dopamine neurons operate in distinct temporal domains using multimodal signaling. J Neurosci 25:5013-5023.

Lewis BL, O’Donnell P (2000) Ventral tegmental area afferents to the prefrontal cortex maintain membrane potential "up" states in pyramidal neurons via D(1) dopamine receptors. Cereb Cortex 10:1168-1175.

Li HF, Kendig JJ (2003) Ethanol withdrawal hyper-responsiveness mediated by NMDA receptors in spinal cord motor neurons. Br J Pharmacol 139:73-80.

Li Q, Wilson WA, Swartzwelder HS (2002) Differential effect of ethanol on NMDA EPSCs in pyramidal cells in the posterior cingulate cortex of juvenile and adult rats. J Neurophysiol 87:705-711.

Lovinger DM, White G, Weight FF (1989) Ethanol inhibits NMDAactivated ion current in hippocampal neurons. Science 243:1721-1724.

Lovinger DM, White G, Weight FF (1990) NMDA receptor-mediated synaptic excitation selectively inhibited by ethanol in hippocampal slice from adult rat. J Neurosci 10:1372-1379.

Maldve RE, Zhang TA, Ferrani-Kile K, Schreiber SS, Lippmann MJ, Snyder GL, Fienberg AA, Leslie SW, Gonzales RA, Morrisett RA (2002) DARPP-32 and regulation of the ethanol sensitivity of NMDA receptors in the nucleus accumbens. Nat Neurosci 5:641-648.

Mameli M, Zamudio PA, Carta M, Valenzuela CF (2005) Developmentally regulated actions of alcohol on hippocampal glutamatergic transmission. J Neurosci 25:8027-8036.

Mangiavacchi S, Wolf ME (2004) D1 dopamine receptor stimulation increases the rate of AMPA receptor insertion onto the surface of cultured nucleus accumbens neurons through a pathway dependent on protein kinase A. J Neurochem 88:1261-1271.

Marshall L, Helgadottir H, Molle M, Born J (2006) Boosting slow oscillations during sleep potentiates memory. Nature 444:610-613.

Matsushita N, Okada H, Yasoshima Y, Takahashi K, Kiuchi K, Kobayashi K (2002) Dynamics of tyrosine hydroxylase promoter activity during midbrain dopaminergic neuron development. J Neurochem 82:295-304.

Melchior CL, Glasky AJ, Ritzmann RF (1993) A low dose of ethanol impairs working memory in mice in a win-shift foraging paradigm. Alcohol 10:491-493.

Miyakawa T, Yagi T, Kitazawa H, Yasuda M, Kawai N, Tsuboi K, Niki H (1997) Fyn-kinase as a determinant of ethanol sensitivity: relation to NMDA-receptor function. Science 278:698-701.

Morrisett RA (1994) Potentiation of N-methyl-D-aspartate receptordependent afterdischarges in rat dentate gyrus following in vitro ethanol withdrawal. Neurosci Lett 167:175-178.

Moselhy HF, Georgiou G, Kahn A (2001) Frontal lobe changes in alcoholism: a review of the literature. Alcohol Alcohol 36:357-368.

Nie Z, Madamba SG, Siggins GR (1994) Ethanol inhibits glutamatergic neurotransmission in nucleus accumbens neurons by multiple mechanisms. J Pharmacol Exp Ther 271:1566-1573.

O’Donnell P, Grace AA (1995) Synaptic interactions among excitatory afferents to nucleus accumbens neurons: hippocampal gating of prefrontal cortical input. J Neurosci 15:3622-3639.

Okamoto T, Harnett MT, Morikawa H (2006) Hyperpolarization-activated cation current (Ih) is an ethanol target in midbrain dopamine neurons of mice. J Neurophysiol 95:619-626.

Poelchen W, Nieber K, Illes P (1997) Tolerance to inhibition by ethanol of $\mathrm{N}$-methyl-D-aspartate-induced depolarization in rat locus coeruleus neurons in vitro. Eur J Pharmacol 332:267-271.

Ridderinkhof KR, Vlugt Y, Bramlage A, Spaan M, Elton M, Snel J, Band GP (2002) Alcohol consumption impairs detection of performance errors in mediofrontal cortex. Science 298:2209-2211.

Roberto M, Schweitzer P, Madamba SG, Stouffer DG, Parsons LH, Siggins GR (2004) Acute and chronic ethanol alter glutamatergic transmission in rat central amygdala: an in vitro and in vivo analysis. J Neurosci 24:1594-1603.

Rossetti ZL, Carboni S, Stancampiano R, Sori P, Pepeu G, Fadda F (2002) Bidirectional modulation of spatial working memory by ethanol. Alcohol Clin Exp Res 26:181-185.

Sceniak MP, Maciver MB (2006) Cellular actions of urethane on rat visual cortical neurons in vitro. J Neurophysiol 95:3865-3874.

Schultz W, Dayan P, Montague PR (1997) A neural substrate of prediction and reward. Science 275:1593-1599.

Schwarz E, Kielholz P, Hobi V, Goldberg L, Gilsdorf U, Hofstetter M, Ladewig D, Miest PC, Reggiani G, Richter R (1981) Alcohol-induced biphasic background and stimulus-elicited EEG changes in relation to blood alcohol levels. Int J Clin Pharmacol Ther Toxicol 19:102-111.

Seamans JK, Yang CR (2004) The principal features and mechanisms of dopamine modulation in the prefrontal cortex. Prog Neurobiol 74:1-58.

Seamans JK, Nogueira L, Lavin A (2003) Synaptic basis of persistent activity in prefrontal cortex in vivo and in organotypic cultures. Cereb Cortex 13:1242-1250.

Skeberdis VA, Lan Jy, Zheng X, Zukin RS, Bennett MV (2001) Insulin promotes rapid delivery of $\mathrm{N}$-methyl-D-aspartate receptors to the cell surface by exocytosis. Proc Natl Acad Sci USA 98:3561-3566.

Steriade M (2001) Impact of network activities on neuronal properties in corticothalamic systems. J Neurophysiol 86:1-39.

Steriade M, Nunez A, Amzica F (1993) A novel slow ( $<1 \mathrm{~Hz}$ ) oscillation of neocortical neurons in vivo: depolarizing and hyperpolarizing components. J Neurosci 13:3252-3265.

Sullivan EV, Pfefferbaum A (2005) Neurocircuitry in alcoholism: a substrate of disruption and repair. Psychopharmacology (Berl) 180:583-594.

Sun X, Zhao Y, Wolf ME (2005) Dopamine receptor stimulation modulates AMPA receptor synaptic insertion in prefrontal cortex neurons. J Neurosci 25:7342-7351.

Vissel B, Krupp JJ, Heinemann SF, Westbrook GL (2001) A use-dependent tyrosine dephosphorylation of NMDA receptors is independent of ion flux. Nat Neurosci 4:587-596.

Wang XJ (1999) Synaptic basis of cortical persistent activity: the importance of NMDA receptors to working memory. J Neurosci 19:9587-9603.

Wang YT, Salter MW (1994) Regulation of NMDA receptors by tyrosine kinases and phosphatases. Nature 369:233-235.

Weiner JL, Valenzuela CF (2006) Ethanol modulation of GABAergic transmission: the view from the slice. Pharmacol Ther 111:533-554.

Weiner JL, Dunwiddie TV, Valenzuela CF (1999) Ethanol inhibition of synaptically evoked kainate responses in rat hippocampal CA3 pyramidal neurons 56:85-90.

Wirkner K, Krause T, Koles L, Thummler S, Al-Khrasani M, Illes P (2004) D1 but not D2 dopamine receptors or adrenoceptors mediate dopamineinduced potentiation of $\mathrm{N}$-methyl-D-aspartate currents in the rat prefrontal cortex. Neurosci Lett 372:89-93.

Wolf JA, Moyer JT, Lazarewicz MT, Contreras D, Benoit-Marand M, O'Donnell P, Finkel LH (2005) NMDA/AMPA ratio impacts state transitions and entrainment to oscillations in a computational model of the nucleus accumbens medium spiny projection neuron. J Neurosci 25:9080-9095.

Xu M, Woodward JJ (2006) Ethanol inhibition of NMDA receptors under conditions of altered protein kinase A activity. J Neurochem 96:1760-1767.

Yaka R, Thornton C, Vagts AJ, Phamluong K, Bonci A, Ron D (2002) NMDA receptor function is regulated by the inhibitory scaffolding protein, RACK1. Proc Natl Acad Sci USA 99:5710-5715.

Yaka R, Phamluong K, Ron D (2003) Scaffolding of Fyn kinase to the NMDA receptor determines brain region sensitivity to ethanol. J Neurosci 23:3623-3632.

Zhang TA, Hendricson AW, Morrisett RA (2005) Dual synaptic sites of $\mathrm{D}(1)$-dopaminergic regulation of ethanol sensitivity of NMDA receptors in nucleus accumbens. Synapse 58:30-44. 